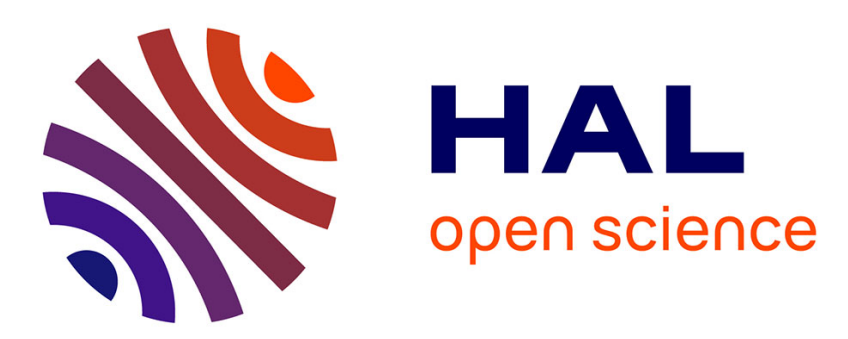

\title{
System Properties and Control of Turbocharged Diesel Engines with High-and Low-Pressure EGR
}

\author{
M. Mrosek, R. Isermann
}

\section{To cite this version:}

M. Mrosek, R. Isermann. System Properties and Control of Turbocharged Diesel Engines with Highand Low-Pressure EGR. Oil \& Gas Science and Technology - Revue d'IFP Energies nouvelles, 2011, 66 (4), pp.587-598. 10.2516/ogst/2011131 . hal-01937416

\section{HAL Id: hal-01937416 https://hal.science/hal-01937416}

Submitted on 28 Nov 2018

HAL is a multi-disciplinary open access archive for the deposit and dissemination of scientific research documents, whether they are published or not. The documents may come from teaching and research institutions in France or abroad, or from public or private research centers.
L'archive ouverte pluridisciplinaire HAL, est destinée au dépôt et à la diffusion de documents scientifiques de niveau recherche, publiés ou non, émanant des établissements d'enseignement et de recherche français ou étrangers, des laboratoires publics ou privés. 


\title{
System Properties and Control of Turbocharged Diesel Engines with High- and Low-Pressure EGR
}

\author{
M. Mrosek* and R. Isermann \\ Institute of Automatic Control, Technische Universität Darmstadt, Landgraf-Georg-Str. 4, 64283 Darmstadt - Germany \\ e-mail: mmrosek@iat.tu-darmstadt.de - risermann@iat.tu-darmstadt.de \\ * Corresponding author
}

\begin{abstract}
Résumé - Propriétés système et contrôle de moteurs Diesel turbocompressés avec EGR haute et basse pression - Une extension du système d'air et d'échappement au moyen d'EGR basse pression peut potentiellement réduire significativement les émissions de $\mathrm{NO}_{x}$. À côté de l'EGR haute pression refroidi et du turbocompresseur à turbine à géométrie variable, l'EGR basse pression introduit un degré de liberté supplémentaire pour contrôler la charge du cylindre. Cette complexité croissante du système d'air peut être traitée à l'aide de structures de contrôle et d'un étalonnage de régulateur basés sur des modèles. Ses propriétés statiques et dynamiques sont étudiées. En dehors des couplages statiques dans la boucle d'air classique, des couplages additionnels apparaissent. Une approche de contrôle décentralisé PI(D) avec séquencement de gain est choisie pour réguler les débits massiques d'air et d'EGR haute pression, ainsi que la pression d'air de suralimentation. Une calibration du contrôle automatisé, basée sur un modèle à valeur moyenne semi-physique de complexité réduite, est présentée. La configuration d'un système à double boucle d'EGR est introduite. Les cartographies de contrôle dépendent du point de fonctionnement du moteur et sont étalonnées par une linéarisation locale du modèle semiphysique. En outre, un contrôle semi-physique est capable de réguler le débit massique d'air à peu près uniquement par l'intermédiaire des actionneurs de l'EGR basse pression. Cette régulation prend en compte implicitement des couplages entre la pression d'air de suralimentation, l'EGR haute pression et le système d'EGR basse pression. Enfin, des résultats de banc d'essai sont présentés.
\end{abstract}

\begin{abstract}
System Properties and Control of Turbocharged Diesel Engines with High- and LowPressure EGR - An extension of the air-and exhaust-system with a low-pressure EGR has the potential to significantly reduce the $\mathrm{NO}_{x}$ emissions. Besides a cooled high-pressure EGR and the turbocharger with variable geometry turbine, the low-pressure EGR introduces an additional degree of freedom to control the cylinder charge. This increasing complexity of the air system can be handled with model based control structures and a model based controller calibration. Its static and dynamic properties are investigated. Besides the static couplings in the classical air path, additional couplings appear. A decentralised gain scheduled PI $(D)$-control approach is chosen to control the variables air mass flow rate, high-pressure EGR mass flow rate and charge air pressure. An automated controller calibration, based on a semi-physical mean value model of reduced complexity, is presented. The controller maps depend on the engine operation point and are calibrated by a local linearisation of the semi-physical model. Further, a semi-physical control is capable to almost solely control the air mass flow rate via the low-pressure EGR actuators. This control implicitly accounts for couplings between charge air pressure, high-pressure EGR and the low-pressure EGR system. Finally testbed results are shown.
\end{abstract}




\section{INTRODUCTION}

In order to fulfil future emission standards, comprehensive methods are necessary to reduce the emissions of Diesel engines. A Diesel Particulate Filter (DPF) can become obligatory in many engine configurations to comply with the Euro 5 emission standards. Then the development emphasises on the further reduction of the $\mathrm{NO}_{x}$ emissions. Thereby the objective is a concept being preferably neutral in cost and fuel consumption. A Selective Catalytic Reduction system (SCR) has the potential to hold the future emission limits for the $\mathrm{NO}_{x}$ emissions and might be necessary for Diesel combustion engines with medium to high power. However, SCR-systems are complex and bear too large additional costs for small to mid size engines with lower overall system costs. Besides engines with lower power are able to achieve the emission regulations without SCR-systems. A mix of different engine modifications like optimised combustion modes, advantages in injection technology, two stage turbo charging and enhanced EGR-concepts can fulfil the future emission regulations without an expensive SCR-system [1].

An effective in-cylinder method to reduce the $\mathrm{NO}_{x}$ emissions is to attain high exhaust-gas-recirculation rates at high cylinder charges. This allows the absence or the minimisation of exhaust gas aftertreatment systems. A high cylinder charge demands a large gas density in the intake manifold with preferably low temperatures and high charge air pressures. One way to achieve this is a Low-Pressure Exhaust-Gas-Recirculation (LP-EGR). Since the the recirculated exhaust gas is cooled three times, this LP-EGR can significantly reduce the charge temperature. At first the gas is expanded via the turbocharger turbine and then it is cooled by the LP-EGR cooler and the charge air cooler. It will be shown that the LP-EGR also decouples the charge air pressure from the EGR-rate. The comparison to a HP-EGR system can show a wider operation range with respect to air mass flow rate and charge air pressure. A further advantage is the better mixture between the exhaust gas and the fresh air. Further the turbocharger can be calibrated to a favourable operation point with a higher effectiveness [2]. At some engine operation points, the low temperature of the LP-EGR is undesired and can be risen by an additional mixture with HP-EGR [1]. Therefore the combination of a high- and a low-pressure EGR seems to be an effective method to significantly reduce the $\mathrm{NO}_{x}$ emissions.

The LP-EGR further increases the system complexity for engine control and diagnosis. While there is a significant amount of research performed on the HP-EGR system with VGT-turbocharger, there are only a few publications concerning the dual path EGR system. This contribution analyses the system properties of the more complex intake and exhaust system and summarises previous research. Based upon a given control concept with decentralised PI(D)-controllers for HP-EGR and VGT-turbocharger, an enhanced control concept is derived and experimentally evaluated for the dual path EGR system.

\section{SYSTEM CONFIGURATION}

The system configuration for a two path EGR-system is shown in Figure 1. The air- and exhaust system of an Opel DTH-Z19 common rail Diesel engine at the test bench of the institute of automatic control is extended with a LPEGR path. Additional to the series configuration a Diesel Particulate Filter (DPF), a LP-EGR cooler, a LP-EGR-valve and an exhaust throttle valve are mounted to the engine. The LP-EGR cooler was kindly provided by Behr and is connected to the testbed cooling system. With support of DES (Diesel Exhaust Systems GmbH) a DPF solution with electric regeneration is retrofitted.

The LP-EGR mass flow rate $\dot{m}_{\text {lp-egr }}$ depends on the position of the LP-EGR-valve $s_{\text {lp-egr }}$ and the proportion of the pressures $p_{1}$ and $p_{\text {lp-egr }}$, respectively $p_{5}$. Closing the exhaust throttle valve $s_{\text {eth }}$ leads to a rise in the pressure $p_{5}$ and in combination with an opened LP-EGR-valve to a rise in the LP-EGR mass flow rate. Low pressures in the exhaust system are desired to minimise the charge cycle losses. Hence the exhaust throttle valve actuator is only active when the LP-EGR-valve is fully opened. An actuator coupling leads to the virtual actuator position $s_{\mathrm{lp} \text {-egr/eth [3]. }}$

All actuator-positions are normalised between 0 and 1 . Both EGR-valves are closed at position 0 and opened at a value of 1 . The throttle valves' positions are defined vice versa, i.e. 1 for closed and 0 for opened. Regarding the VGT-actuator, a position of 0 reflects an opened position of the guide vanes and at position 1 the vanes are closed. For the combined actuator $s_{\text {lp-egr/eth }}=[0, \ldots, 0.5]$ corresponds to $s_{\text {lp-egr }}=[0, \ldots, 1]$ with $s_{\text {eth }}=0$. Further $s_{\mathrm{lp}-\mathrm{ger} / \mathrm{eth}}=[0.5, \ldots, 1]$ corresponds to $s_{\mathrm{lp}-\mathrm{egr}}$ open with an exhaust throttle valve position between $[0, \ldots, 1]$.

\section{SEMI-PHYSICAL AIR PATH MODEL OF REDUCED ORDER}

The gas composition within the combustion chamber is one of the manipulated variables for a feed-forward control of the emission formation. This calibrated gas composition must be provided also in transient engine operation. Therefore a control system with a good dynamical performance is necessary.

The conventional intake- and exhaust-system with HPEGR-valve and VGT-actuator is already a nonlinear coupled multi-variable system. Thus, a model based methodology is necessary to gain system understanding and to apply analytical methods for multi-variable control. [4] utilises local affine models (LOLIMOT) to model the system and for an automated controller calibration. Further, control oriented 


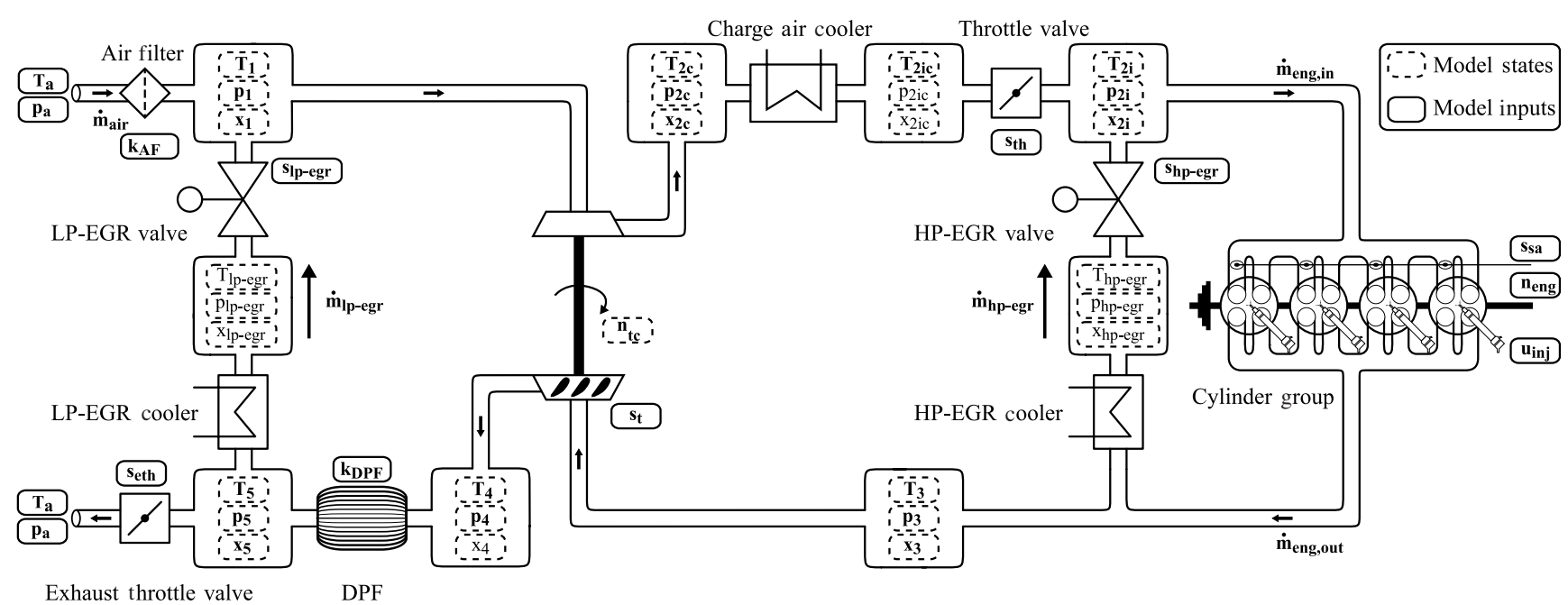

System configuration and model structure of the air- and exhaust-system for a two path EGR-system with VGT turbocharger.

air path models of limited complexity, like a mean value model with lumped parameters, have shown good results for control design and calibration [5-8].

The additional LP-EGR path further increases the system complexity. Since the properties of this configuration are not completely investigated, a semi-physical mean value model is developed to get insight into the system properties.

The components in the air- and exhaust system are modelled with lumped parameters as a sequence of storage elements and flow restrictions [9-12]. A novel turbocharger model based on the mean line theory is presented in [13]. It overcomes the drawback of poor extrapolation capabilities for commonly used models based on characteristic maps. This model is used to describe the static and dynamic properties of the turbocharger and is implemented in the mean value model. The model states in the $i$ storages are the pressures $p_{i}$ and temperatures $T_{i}$. Further the oxygen concentrations $x_{i}$ in each storage element describe the dynamic impact of the two EGR-paths. Finally the turbocharger speed $n_{\mathrm{tc}}$ is a further model state.

In general, modelling is characterised as a trade-off between complexity and model precision. A higher model complexity complicates the controller calibration and costs more computation time. Therefore only the bold printed states in Figure 1 are modelled. The dynamic influences of small storages can be considered as much faster than the one of large storages. Consequently all storages between coolers and flow restrictions with variable cross section are neglected. To account for the exhaust back pressure caused by the DPF, the storage after the turbine with the states $p_{4}$ and $T_{4}$ is introduced. Especially at testbed operation the charge air cooler can introduce a large thermal storage capacity, which is modelled by the heat storage mass with the additional state $T_{2 \text { ic }}$ [14]. Model inputs are the positions of the air path actuators and additionally the ambient temperature $T_{\mathrm{a}}$ and the ambient pressure $p_{\mathrm{a}}$. The engine operation point is determined by the engine speed $n_{\text {eng }}$ and the desired injection quantity $u_{\text {inj }}$. To simulate the influence of a loaded DPF and a plugged air filter, the loading factors $k_{\mathrm{DPF}}$ and $k_{\mathrm{AF}}$ are introduced as additional model inputs. Generally the physical laws for air path modelling are well established. A key issue in modelling is the model parameterisation. [15] and [14] give a methodology to parameterise a mean value engine model. Aspects like the model uncertainty to sensor precision, the measurement chain, suitable excitation signals, data preprocessing and especially the aerodynamic turbocharger power parameterisation are regarded.

Figure 2 shows a dataset to validate the mean value model of 19th order at an engine operation point of $n_{\mathrm{eng}}=$ $3000 \mathrm{~min}^{-1}$ and $u_{\text {inj }}=5 \mathrm{~mm}^{3} / \mathrm{cyc}$. The HP-EGR-valve is excited with an Amplitude modulated Pseudo Random Binary Signal (APRBS) at two different positions of

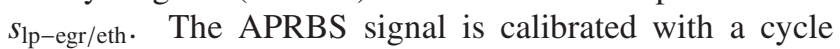
time of $1 \mathrm{~s}$, a signal length of 511 states and uniformly distributed amplitudes between 0 and 1, see [16]. The simulation results reflect $p_{2 \mathrm{i}}$ as well as $\dot{m}_{\text {air }}$ in static and dynamic characteristics. The comparison between the simulated and the measured quantities shows a good agreement. Both the stationary as well as the dynamical system behaviour are met. In advance to the next section, the corresponding values for $\dot{m}_{\mathrm{hp} \text {-egr }}$ and $\dot{m}_{\mathrm{lp-egr}}$ show the system couplings. Similar results are obtained for other engine operation points. 

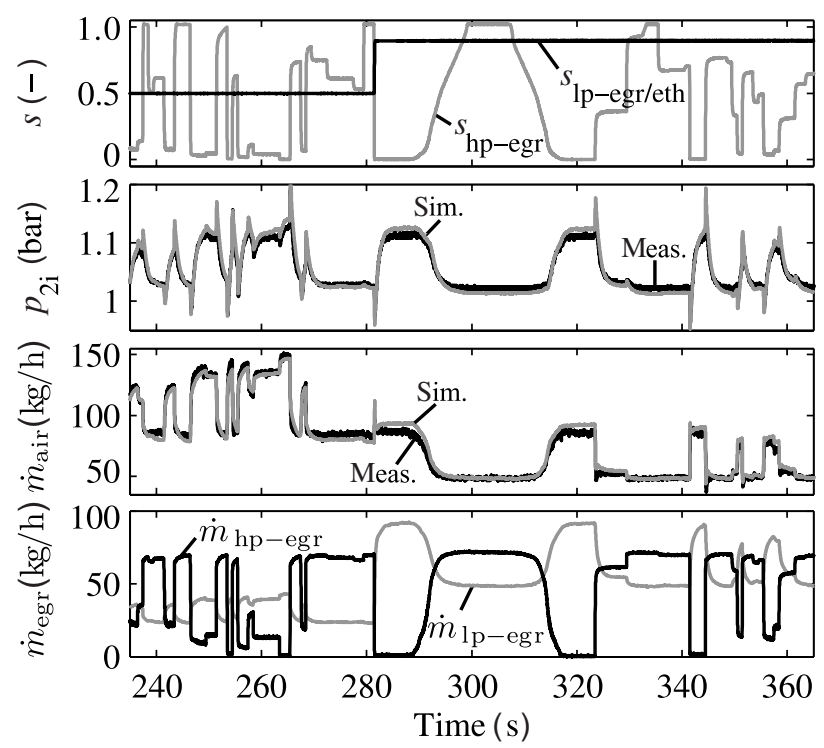

Figure 2

Model validation for the air- and exhaust-path with varying $s_{\mathrm{hp}-\text { egr }}$ and $s_{\mathrm{lp} \text {-egr/eth }}$ at an engine operation point $n_{\mathrm{eng}}=$ $3000 \mathrm{~min}^{-1}$ and $u_{\text {inj }}=5 \mathrm{~mm}^{3} /$ cyc.

\section{STATIC SYSTEM COUPLINGS OF THE TWO PATH EGR-SYSTEM}

In this section the static system couplings of the two EGRsystems are investigated. While the system properties of the classical HP-EGR system are sufficiently examined, an investigation for the LP-EGR system will be given in the following. A first research of the system couplings between the VGT-actuator $s_{\mathrm{t}}$ and the HP-EGR valve $s_{\mathrm{hp} \text {-egr }}$ is presented by models for the static process gains in [17]. Then a more detailed investigation about these couplings with the simulated process gains and step responses is given in [18] with regard to the HP-EGR rate and the in cylinder oxygen to air ratio. In [19] the process gains and the time constants are given as the parameters of identified grey-box models, while [8] illustrates the system properties by the proportional gain maps of the air path PI(D)-controllers.

Analysing the couplings of the two path EGR system results in a more complex system. Hence the HP-EGR system properties are recapitulated by means of quasi stationary simulation results. Then the system properties of the LP-EGR system are analysed. Figures 3 and 4 show the static system couplings of the air- and exhaust-system extended with two EGR-paths at an engine operation point of $n_{\mathrm{eng}}=2200 \mathrm{~min}^{-1}$ and $u_{\mathrm{inj}}=15 \mathrm{~mm}^{3} /$ cyc.

The couplings between the VGT-actuator, $\dot{m}_{\text {air }}$ and the charge air pressure $p_{2 \mathrm{i}}$ at different positions $s_{\mathrm{hp} \text {-egr }}$ are illustrated in Figure 3. The main influence of the guiding
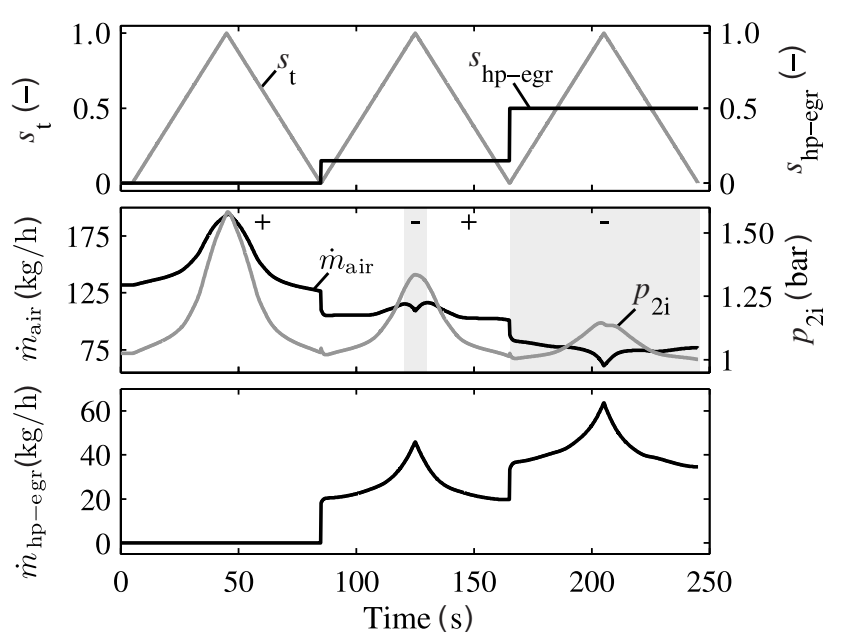

Figure 3

Quasi stationary simulation results to show the static couplings of the two path EGR-system. Variation of $s_{\mathrm{t}}$ at different positions of $s_{\mathrm{hp}-\mathrm{egr}} ; s_{\mathrm{lp}-\mathrm{egr}}$ closed.

vanes' position is the charge air pressure. The corresponding process gain decreases when the HP-EGR-valve opens. Regarding the influence to $\dot{m}_{\text {air }}$, a change in the sign of the process gain is an interesting observation. When the HP-EGR-valve is closed, closing the guide vanes lead to an optimised flow angle at the turbine and an acceleration of the turbocharger shaft. A higher gas mass flow rate is pumped through the compressor. Then a further opening of the HPEGR-valve to a position of 0.15 and closing $s_{\mathrm{t}}$ in a ramp lets $\dot{m}_{\text {air }}$ rise in the beginning. When $s_{\mathrm{t}}$ is further opened than 0.8 , the gain of $\dot{m}_{\text {air }}$ changes its sign. Closing $s_{\mathrm{t}}$ more leads to a decrease in $\dot{m}_{\text {air }}$. Opening $s_{\text {hp-egr }}$ to 0.5 results in a negative gain between $s_{\mathrm{t}}$ and $\dot{m}_{\text {air }}$. This change of sign in the coupling has multiple effects and can be explained as follows. The air mass flow rate can be stationary given by the balance equation

$$
\dot{m}_{\mathrm{air}}=\dot{m}_{\mathrm{eng}, \text { in }}-\dot{m}_{\mathrm{hp}-\mathrm{egr}}-\dot{m}_{\mathrm{lp}-\mathrm{egr}}
$$

with the mass flow rate entering the engine $\dot{m}_{\text {eng,in. In the }}$ considered case the LP-EGR valve is closed, thus $\dot{m}_{\text {lp-egr }}$ is zero. The mass flow rate entering the engine is roughly proportional to the gas density in the intake manifold and therefore proportional to the intake pressure and reciprocal to the intake temperature. When the turbine's vanes close, the flow angle changes and the turbine has a narrower flow restriction. Consequently the pressure in the exhaust manifold $p_{3}$ rises. Hence a larger mass flow rate passes the HP-EGR valve and the mass flow rate through the turbine decreases. On the other hand the VGT closing improves the turbine flow angle and accelerates the turbocharger, which results in a higher charge air pressure. Then the rise in charge air 


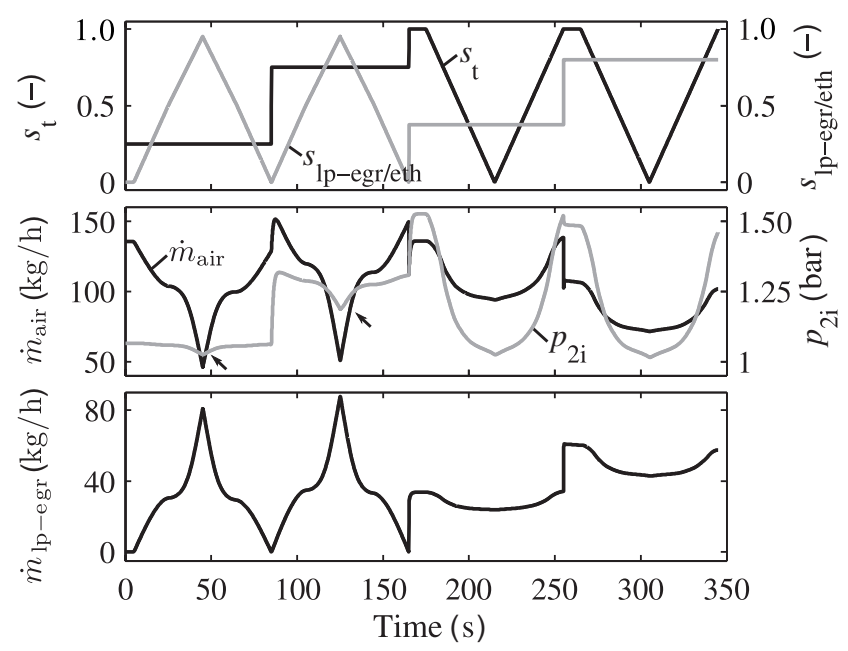

Figure 4

Quasi stationary simulation results to show the static couplings of the two path EGR-system. Variation of $s_{\mathrm{t}}$ and $s_{\mathrm{lp}-\mathrm{egr} / \mathrm{eth}}$; $s_{\text {hp-egr }}$ closed.

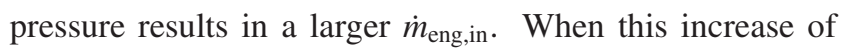
$\dot{m}_{\text {eng,in }}$ is larger than the rise in $\dot{m}_{\mathrm{hp}-\text { egr }}$, the coupling between $s_{\mathrm{t}}$ and $\dot{m}_{\text {air }}$ is positive. Otherwise this coupling is negative and $\dot{m}_{\text {air }}$ sinks with a further closing of $s_{\mathrm{t}}$. With a given $p_{3}$ and $p_{2 \mathrm{i}}$ the rise in $\dot{m}_{\mathrm{hp} \text {-egr }}$ is mainly determined by the position $s_{\text {hp-egr }}$. At some valve positions the mass flow rate $\dot{m}_{\text {hp-egr }}$ rises stronger than $\dot{m}_{\text {eng,in }}$ increases via the change in $p_{2 \mathrm{i}}$. Hence the sign of the coupling changes. Furthermore the temperatures in the intake and exhaust manifold can influence this couplings via the gas densities, which influence the mass flow rate entering the engine and as shown in [15] the turbine power.

Regarding the influence of $s_{\mathrm{t}}$ to $\dot{m}_{\mathrm{hp} \text {-egr }}$ throughout gives a positive coupling. Obviously for a closed $s_{\mathrm{hp}-\text { egr }}$ the coupling is zero. These shown couplings agree well with the investigations presented in [8, 17-19].

Figure 4 points out the couplings between the LP-EGRpath and $s_{\mathrm{t}}$. Variations of the LP-EGR mass flow rate have only small couplings with the charge air pressure. These couplings are only considerable when the exhaust throttle valve is almost closed at a time of $45 \mathrm{~s}$ and $125 \mathrm{~s}$, as indicated by an arrow. Then a small influence in the pressure $p_{2 \mathrm{i}}$ can be noticed. The decreased exhaust throttle area results in an exhaust gas back pressure $p_{5}$ rise and a change of the pressure ratio over the turbine. This changed pressure ratio changes the gas density before the turbine and therefore the turbine power modelled with Euler's equation for turbomachinery, see [15]. Reducing $\dot{m}_{\text {air }}$ via a change in the guide vane position $s_{\mathrm{t}}$ significantly reduces $\dot{m}_{\mathrm{lp}-\mathrm{egr}}$. During the first $s_{\mathrm{t}}$-ramp, $\dot{m}_{\text {air }}$ is reduced from $135 \mathrm{~kg} / \mathrm{h}$ to $94 \mathrm{~kg} / \mathrm{h}$ which results in a drop of $\dot{m}_{\text {lp-egr }}$ from $35 \mathrm{~kg} / \mathrm{h}$ to $23 \mathrm{~kg} / \mathrm{h}$.

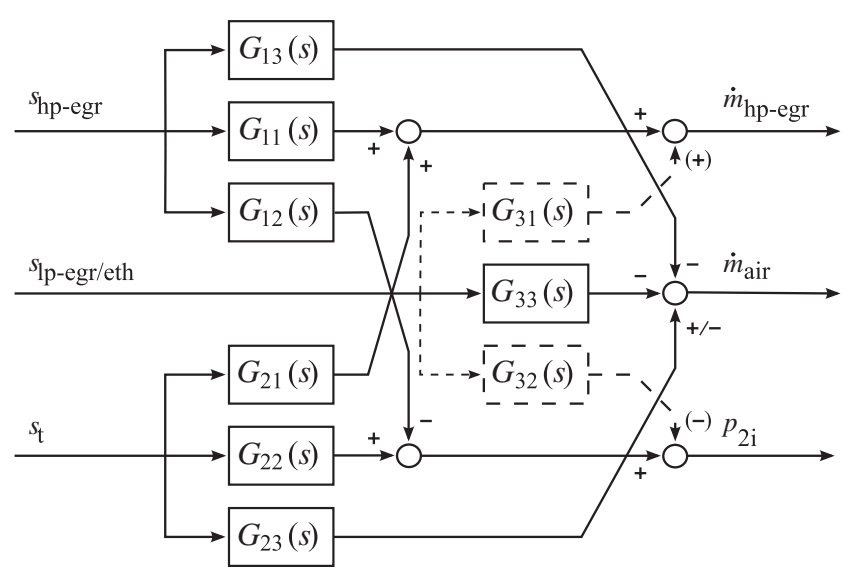

Figure 5

Couplings between the two EGR paths and the VGTturbocharger in p-canonical structure.

A decrease in $\dot{m}_{\text {air }}$ leads on the one hand to a lower pressure drop at the air filter and therefore to a higher pressure $p_{1}$. On the other hand the mass flow rate exiting the exhaust gas system through the exhaust throttle plate decreases too. Therefore the pressure $p_{5}$ sinks. As a combination of these two effects the pressure ratio over the LP-EGR-valve drops. This causes the decrease in $\dot{m}_{\text {lp-egr }}$. When $\dot{m}_{\text {air }}$ rises the same effects occur in different direction and $\dot{m}_{\mathrm{lp} \text {-egr }}$ also rises.

The coupling between high- and low-pressure EGR in Figure 2 shows a similar effect for the interaction. Closing the HP-EGR-valve leads to a rise in the mass flow rate entering and exiting the intake- and exhaust-system and therefore changes the pressures ratio over the LP-EGR-valve. Therefore the effect of an APRBS excitation of $s_{\mathrm{hp} \text {-egr }}$ is also visible in $\dot{m}_{\text {lp-egr. }}$. The LP-EGR-path has only a coupling to $\dot{m}_{\mathrm{hp}-\text { egr }}$ when the exhaust throttle valve rises the exhaust back pressure noticeable. This coupling is not shown here.

Finally $s_{\text {hp-egr }}$ has a negative coupling to $p_{2 \mathrm{i}}$, a negative coupling to $\dot{m}_{\text {air }}$ and a positive coupling to $\dot{m}_{\mathrm{hp} \text {-egr. }}$ Figure 5 summarises the couplings of the dual path EGR-system in p-canonical structure. The weak couplings of $s_{\text {lp-egr/eth }}$ are displayed in a dashed line. The sign of the coupling $G_{23}(s)$ depends on the engine operation point and the position of $s_{\text {hp-egr }}$, see Figure 3.

\subsection{Operation Range of HP- and LP-EGR-Path}

The operation range in the $\dot{m}_{\text {air }} / p_{2 \mathrm{i}}$-plane considering exclusively one EGR-path at the engine operation point of $n_{\mathrm{eng}}=$ $2000 \mathrm{~min}^{-1}$ and $u_{\text {inj }}=20 \mathrm{~mm}^{3} /$ cyc is shown in Figure 6 . For the HP-EGR-system it can be seen that the maximal possible charge air pressure $p_{2 \mathrm{i}}$ decreases from 1.55 bar to 1.05 bar when the HP-EGR-valve fully opens. Also the change in the sign of the gain from $s_{\mathrm{t}}$ to $\dot{m}_{\text {air }}$ can be 


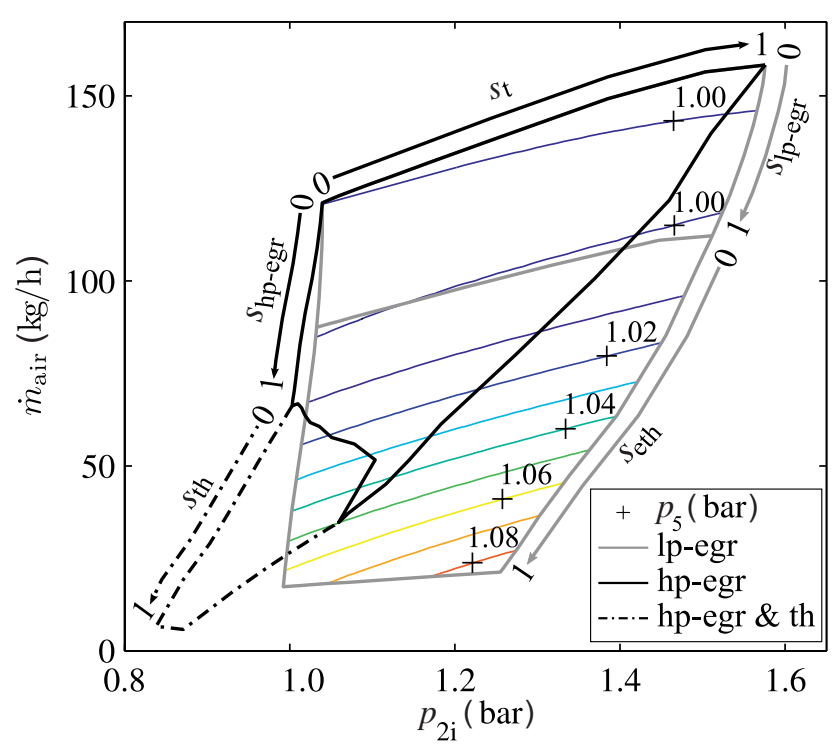

Figure 6

Operation range of either HP- or LP-EGR with contour lines of equal $p_{5}$ at $n_{\text {eng }}=2000 \mathrm{~min}^{-1}$ and $u_{\text {inj }}=20 \mathrm{~mm}^{3} / \mathrm{cyc}$.

observed. When $s_{\mathrm{hp}-\mathrm{egr}}$ is closed, closing $s_{\mathrm{t}}$ results in an increase of $\dot{m}_{\text {air }}$ from 120 to $160 \mathrm{~kg} / \mathrm{h}$. For a fully opened HP-EGR-valve, closing $s_{\mathrm{t}}$ decreases $\dot{m}_{\text {air }}$ from $60 \mathrm{~kg} / \mathrm{h}$ to 25 $\mathrm{kg} / \mathrm{h}$. Lower air mass flow rates can only be achieved by increasing the pressure ratio via the throttle valve $s_{\text {th }}$ over a fully opened HP-EGR-valve, as shown in the dashed area. At low values of $\dot{m}_{\text {air }}$ the possible operation range becomes very narrow. When high EGR-rates are required, this narrow operation range complicates the closed loop control.

Alternatively the LP-EGR-path decouples $\dot{m}_{\text {air }}$ from $p_{2 \mathrm{i}}$. The grey encircled operation range is larger than the operation range in a HP-EGR-configuration. Caused by the decoupling, closing $s_{\mathrm{t}}$ always increases $\dot{m}_{\text {air }}$. When the exhaust throttle valve closes, a rise in the pressure $p_{5}$ to 1.08 bar can be observed. Lowering $\dot{m}_{\text {air }}$ via the LP-EGR-path causes a decrease in $p_{2 \mathrm{i}}$ from 1.55 bar to 1.25 bar. Further investigations need to be spend on the pressure drop of $0.3 \mathrm{bar}$ in $p_{2 \mathrm{i}}$. The rise of $p_{5}$ is an obvious reason, but it accounts only for 0.08 bar. Additionally an operation of the turbocharger in an operation point with lower effectiveness or changes in the available enthalpy over the turbine might cause this loss in charge air pressure. Finally in the area of low values for $\dot{m}_{\text {air }}$ the possible operation range is larger than the one for the HP-EGR configuration.

\subsection{Influence of the Coupled Actuator $s_{\text {lp-egr/eth }}$}

The static characteristics of the coupled actuator $s_{\text {lp-egr/eth }}$ is simulated in Figure $7\left(s_{\mathrm{hp} \text {-egr }}=0\right)$ at four different engine operation points, see Table 1 . The engine operation points
TABLE 1

Considered engine operation points

\begin{tabular}{cccc} 
& $n_{\text {eng }}\left(\mathrm{min}^{-1}\right)$ & $u_{\text {inj }}\left(\mathrm{mm}^{3} / \mathrm{cyc}\right)$ & $\dot{m}_{\text {eng,in }}(\mathrm{kg} / \mathrm{h})$ \\
\hline OP1 & 3000 & 25 & $196, \ldots, 295$ \\
OP2 & 2500 & 20 & $150, \ldots, 195$ \\
OP3 & 2000 & 15 & $116, \ldots, 126$ \\
OP4 & 1500 & 10 & $87, \ldots, 89$ \\
\hline
\end{tabular}

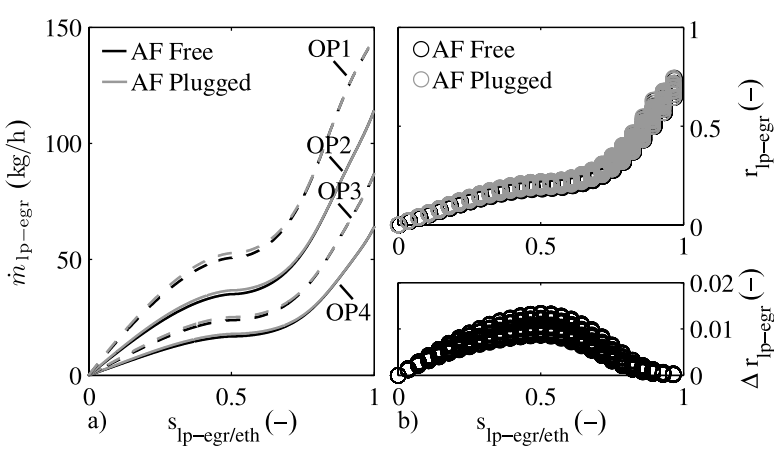

Figure 7

Influence of $s_{1 \mathrm{p}-\mathrm{egr} / \mathrm{eth}}$ to a) the LP-EGR mass flow rate and b) the LP-EGR rate at different engine operation points with a free and a plugged air filter.

mainly differ in the charge air pressure and the air mass flow rate entering the engine $\dot{m}_{\mathrm{eng} \text {,in }}$. Besides the stationary coupling to $\dot{m}_{\mathrm{lp}-\mathrm{egr}}$, the low pressure EGR-rate

$$
r_{\mathrm{lp}-\mathrm{egr}}=\frac{\dot{m}_{\mathrm{lp}-\mathrm{egr}}}{\dot{m}_{\mathrm{lp}-\mathrm{egr}}+\dot{m}_{\mathrm{air}}}
$$

is shown. In addition simulations with a plugged air filter are presented.

Figure $7 \mathrm{a}$ shows a rise in $\dot{m}_{\mathrm{lp}-\mathrm{egr}}$ at operation points with higher mass flow rates entering and exiting the engine. Obviously the gain of the actuator depends highly on the engine operation point and differs by a factor of $3, \ldots, 4$ from OP1 to OP4. Further the characteristic curves show a high nonlinearity. Especially between $s_{\mathrm{lp}-\text { egr/eth }} \approx$ $0.4, \ldots, 0.65$, when the low-pressure EGR valve is almost opened and the exhaust throttle valve starts to close, the curves are very flat. This change in the stationary gain is disadvantageous for linear controllers. Therefore the characteristic of $s_{\mathrm{lp} \text {-egr/eth }}$ is shaped by a characteristic curve, so that there is an almost linear characteristics between the actuator position and the air mass flow rate.

In Figure $7 b$ the LP-EGR-rate is simulated in the whole engine operation range considering a large set of possible combinations of $s_{\mathrm{t}}$ and $s_{\mathrm{hp} \text {-egr }}$. Interestingly $r_{\mathrm{lp} \text {-egr }}$ almost exclusively depends on the position of the actuator $s_{\mathrm{lp}-\mathrm{egr} / \mathrm{eth}}$. This is caused by the previously described couplings of $\dot{m}_{\mathrm{lp}-\text { egr }}$ with $s_{\mathrm{hp} \text {-egr }}$ and $s_{\mathrm{t}} . \dot{m}_{\mathrm{lp} \text {-egr }}$ depends on the gas flow 


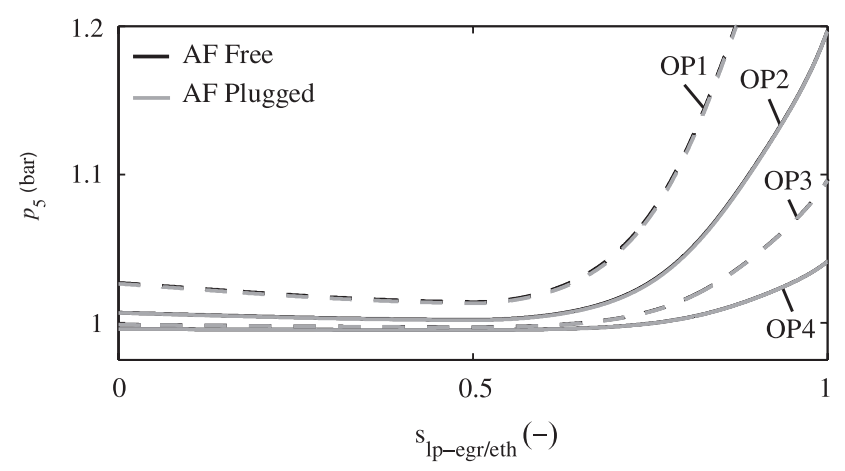

Figure 8

Exhaust pressure at different engine operation points with a free and a plugged air filter.

entering and exiting the system and is therefore proportional to $\dot{m}_{\text {air }}$. Using only the actuator $s_{\text {lp-egr }}$, LP-EGR-rates of $\approx 25 \%$ are possible, higher values for $r_{\text {lp-egr }}$ require the support of $s_{\text {eth }}$.

A plugged air-filter causes an additional pressure drop of $\approx 30$ mbar at $\dot{m}_{\text {air }} \approx 770 \mathrm{~kg} / \mathrm{h} \mathrm{[20].} \mathrm{With} \mathrm{this} \mathrm{information}$ $k_{\mathrm{AF}}$ for a plugged air filter can be determined. In Figure $7 \mathrm{a}$ simulation results for a system with a free and a system with a plugged air filter are shown and only minor differences are noticeable. Only between $s_{\mathrm{lp}-\text { egr/eth }}=0$ and 0.65 small deviations occur. A plugged filter results in a lowered pressure $p_{1}$. At these actuator positions, the plugged air filter has the largest contribution to $\dot{m}_{\mathrm{lp} \text {-egr }}$. When the exhaust throttle plate further closes, the exhaust back pressure $p_{5}$ increases. This primarily influences the pressure ratio over the LP-EGR-valve and the additional lowered pressure $p_{1}$ can be neglected here. The effect of a plugged air filter is not directly visible in $r_{\text {lp-egr. }}$. Therefore the difference $\Delta r_{\mathrm{lp}-\mathrm{egr}}=r_{\mathrm{lp}-\mathrm{egr}, \mathrm{AF}, \mathrm{plug}}-r_{\mathrm{lp}-\mathrm{egr}, \mathrm{AF}, \text { free }}$ specifies the effect of

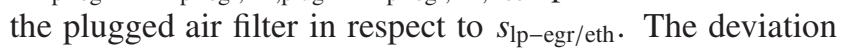
$\Delta r_{\text {lp-egr }}$ rises when $s_{\text {lp-egr }}$ fully opens from $s_{\text {lp-egr/eth }} 0$ to 0.5 . For $s_{\text {lp-egr/eth }}>0.5$ the pressure $p_{5}$ has most influence and the deviation $\Delta r_{\text {lp-egr }}$ sinks, since the effect of the plugged air filter is too small. Therefore the LP-EGR-rate can be regarded as almost invariant to the engine operation point and the loading of the air filter. This observation will be later utilised for a semi-physical control of the LP-EGR-rate.

In Figure 8 the influence of $s_{\text {lp-egr/eth }}$ to the exhaust pressure $p_{5}$ is investigated. The influence on the exhaust pressure can be divided into two regions. First the LP-EGR valve is investigated $\left(s_{\text {lp-egr/eth }}=0, \ldots, 0.5\right)$. When the LP-EGR valve opens, the pressure $p_{5}$ sinks. This can be advantageous for the charge cycle losses. The pressure drop in $p_{5}$ has two reasons. First the increase of $\dot{m}_{\mathrm{lp} \text {-egr }}$ reduces the amount of exhaust gas that has to exit the system via the exhaust throttle plate. Then the low pressure $p_{1}$ implies a suction through

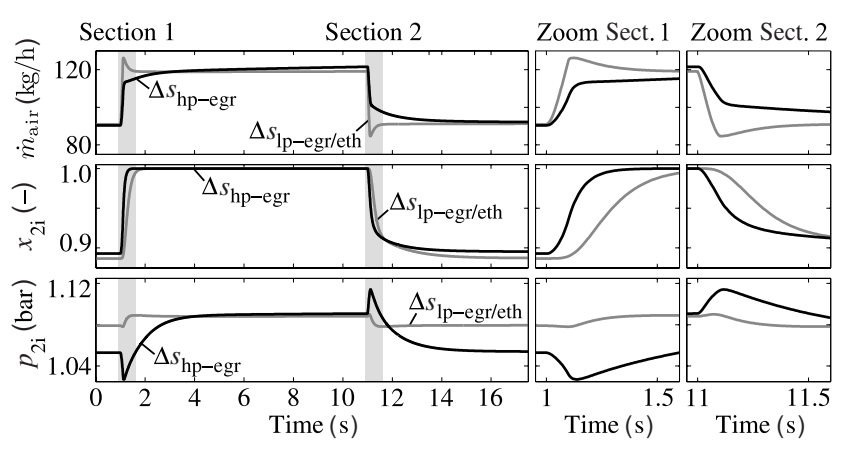

Figure 9

Two step responses for $\Delta s_{\text {lp-egr }}$ and $\Delta s_{\mathrm{hp}-\text { egr }}\left(n_{\text {eng }}=\right.$ $\left.2000 \mathrm{~min}^{-1}, u_{\text {inj }}=15 \mathrm{~mm}^{3} / \mathrm{cyc}\right)$.

the LP-EGR valve and therefore lowers the pressure $p_{5}$. A closing of the exhaust throttle plate $\left(s_{\mathrm{lp}-\text { egr/eth }}=0.5, \ldots, 1\right)$ rises the exhaust pressure $p_{5}$ strongly. Especially at engine operation points with high mass flow rates entering the engine (OP1) the pressure $p_{5}$ is very large. This shows the limitations of this LP-EGR configuration. High lowpressure EGR rates cannot be maintained at engine operation points with large $\dot{m}_{\mathrm{eng}, \text { in }}$ due to the rise in $p_{5}$. Finally the effects of a plugged air filter to $p_{5}$ are not significant.

\section{DYNAMIC PROPERTIES OF THE TWO PATH EGR SYSTEM}

The semi-physical mean value model with lumped parameters yields dynamic models, whereas the dynamics have mainly three sources. First the thermal storages of the engine block are the slowest dynamics. These storages are the engine block, the intercooler, the coolers and the ducts. Further the inertial momentum of the turbocharger introduces the second dynamic effect. Emptying and filling, or changing the gas composition in the storages of the intake- and exhaust system contributes the third and fastest dynamics. Thermal time constants are in the range of several seconds to minutes, the turbocharger time constant is in the range between 0.7 and 3 seconds and the time constants caused by the storages are in the range of $100 \mathrm{~ms}$.

Figure 9 compares the dynamic properties for an HPEGR step and an LP-EGR step of the same size in $\dot{m}_{\text {air }}$. The three sources of dynamics can be observed in the HP-EGR step response. At a time of $1 \mathrm{~s}$ the HP-EGR-valve closes. During the first milliseconds the mass flow rate through the storages in the intake system rises from $90 \mathrm{~kg} / \mathrm{h}$ to $115 \mathrm{~kg} / \mathrm{h}$. Then the turbocharger accelerates and the charge air pressure is rising until a time of $4 \mathrm{~s}$. Between 4 and $10 \mathrm{~s}$ there is still a small rise in $\dot{m}_{\text {air }}$ and $p_{2 \mathrm{i}}$. These slight changes come 
from the modelled thermal storages of the intercooler and the HP-EGR cooler, see [14].

Besides the directly measured quantities $\dot{m}_{\text {air }}$ and $p_{2 \mathrm{i}}$, there are significant dynamics in the gas composition in the intake manifold $x_{2 \mathrm{i}}$. Compared to the HP-EGR path, the LPEGR path has the slower dynamics with respect to $x_{2 \mathrm{i}}$. This is due to by the longer way the exhaust gas has to pass until it reaches the combustion chamber. In Figure 9 this gets obvious for the step response in $x_{2 \mathrm{i}}$. In contrast the LP-EGR-path has a faster dynamical response in the $\dot{m}_{\text {air }}$ step response. This is caused by the direct recirculation of exhaust gas to the intake storage 1 , where the HFM-sensor measuring $\dot{m}_{\text {air }}$ is mounted. In that case, the low-pressure EGR dynamics is mainly determined by the states of volume 1 . On the other hand the step response of $s_{\mathrm{hp} \text {-egr }}$ is delayed by all volumes in the intake system. With regard to $x_{2 \mathrm{i}}$ the HP-EGR has the faster dynamics. A more detailed investigation of the different gas composition dynamics is given in [21]. Moreover the non minimum phase relationship between $s_{\mathrm{hp}-\text { egr }}$ and $p_{2 \mathrm{i}}$ are dynamical system properties.

\section{CONTROL STRUCTURE}

The control of a classical HP-EGR/VGT-system is well investigated and there is a significant amount of publications on this field. A broad overview of different control concepts is given in [22]. Further investigated control concepts for the air path quantities are a model predictive control [23-26], a multi variable robust control [6], a nonlinear internal model control [27] and an observer-based feedback control [28]. A nonlinear control based on a control Lyapunov function is shown in [29] and further extended with integral action in [18]. In [7] different control strategies with mainly decentralised PI controllers are compared with regard to the tailpipe emissions. While the control of a classical HPEGR/VGT-system is well investigated, the combination of a HP-/LP-EGR system with VGT-turbocharger is a recent field of research. In [30] a model-based predictive controller consisting of a state observer, prediction and optimisation algorithms is used to control the two path EGR-system. An optimised actuator position for two controlled variables $\dot{m}_{\text {air }}$ and $p_{2 \mathrm{i}}$, respectively $\dot{m}_{\text {air }}$ and $r_{\text {egr }}$ is determined by a heuristic algorithm. A predictive air management system, having the LP-EGR fraction of the collective EGR-mass flow rate as calibration parameter is presented in [31]. The desired position of the air path actuator is determined by a predictive model based method. Non measured states are modelled by a real time air path model. In the latter approach the charge air pressure is not controlled. Both approaches require high computation time and the algorithms to calculate the values of the manipulated variable are not traceable. Another nonlinear approach based on model inversion of a semi-physical model is presented in [32]. Either HP-EGR or LP-EGR and the charge air pressure are controlled. However, to reach future emission limits both EGR-paths should be controlled simultaneously.

Besides the more sophisticated control concepts, the application of decentralised PID-controllers is widespread in the automotive industry and allows an intuitive adjustment of the controller parameters. This adjustment by the calibration engineer acts as a unique selling point and can consider hard to model influences like the desired torque response or the engine's Noise Vibration Harshness (NVH). Therefore intuitive adjustable controllers are demanded by the automotive industry. [4] present an automated controller calibration for gain scheduled decentralised PID-controllers with the controlled variables $\dot{m}_{\text {air }}$ and $p_{2 \mathrm{i}}$. In the following this approach is extended for the two path EGR system.

Besides the traditional air path configuration with $s_{\mathrm{t}}$ and $s_{\mathrm{hp}-\text { egr }}$ a third actuating variable is introduced with

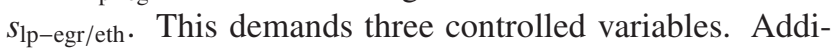
tionally to $\dot{m}_{\text {air }}$ and $p_{2 \mathrm{i}}$ the LP-EGR fraction $\zeta_{\text {lp-egr }}=$ $\dot{m}_{\mathrm{lp}-\mathrm{egr}} /\left(\dot{m}_{\mathrm{lp}-\mathrm{egr}}+\dot{m}_{\mathrm{hp}-\mathrm{egr}}\right)$ can be controlled [31]. After all, both exhaust mass flow rates have to be measured or modelled. In this contribution the choice of $p_{2 \mathrm{i}}, \dot{m}_{\text {air }}$ and $\dot{m}_{\mathrm{hp} \text {-egr }}$ as controlled variables is motivated by the system properties presented in Sections 3 and 4. Controlling $\dot{m}_{\mathrm{hp}-\text { egr }}$ and $\dot{m}_{\text {air }}$ demands a similar engine calibration as the control of the variables $\zeta_{\text {lp-egr }}$ and $\dot{m}_{\text {air }}$. In order to determine $\dot{m}_{\text {hp-egr with }}$ the flow equation for compressible fluids the quantities $p_{2 \mathrm{i}}$, $p_{3}, T_{\mathrm{hp}-\text { egr }}$ and $s_{\mathrm{hp} \text {-egr }}$ have to be measured. Alternatively $T_{\mathrm{hp} \text {-egr }}$ could be modelled. Since the mass flow model is most sensitive to the pressure ratios [14], model inaccuracies in $T_{\mathrm{hp}-\text { egr }}$ have only a small influence to the model quality.

Controlling $\dot{m}_{\mathrm{hp} \text {-egr }}$ with the HP-EGR-valve results in fast response times, since almost no delay through storage elements in the intake system occurs. The effect of a loaded DPF increases the pressure $p_{3}$ and is directly modelled by the flow equation for compressible fluids. The charge air pressure is controlled by the actuator $s_{\mathrm{t}}$. Finally $\dot{m}_{\text {air }}$ is controlled by $s_{\mathrm{lp}-\mathrm{egr} / \mathrm{eth}}$. The throttle valve $s_{\mathrm{th}}$ is always opened and not included in this control structure.

Figure 10 shows the control scheme with the engine process. In order to reflect the nonlinearities of the process, the controller parameters are stored in maps depending on the engine operation point. Since the process responses are delayed to a step in $u_{\text {inj }}$ the controller parameters are filtered by a first order lag (PT1). The desired values for $p_{2 \mathrm{i}}$, $\dot{m}_{\mathrm{hp}-\text { egr }}$ and $\dot{m}_{\text {air }}$ correspond to a feed forward control of the stationary emissions and are stored in characteristic maps depending on the engine operation point. They are filtered with a Reference shaping Filter (RF) to provide a good reference action of the control loop. In order to have a more linear behaviour between the controller and the controlled variable, the output of the $\dot{m}_{\text {air }}$-controller is shaped by a characteristic curve of $s_{\text {lp-egr/eth }}$ which yields a more linear characteristics between $s_{\mathrm{lp} \text {-egr/eth }}$ and $\dot{m}_{\text {air }}$. 


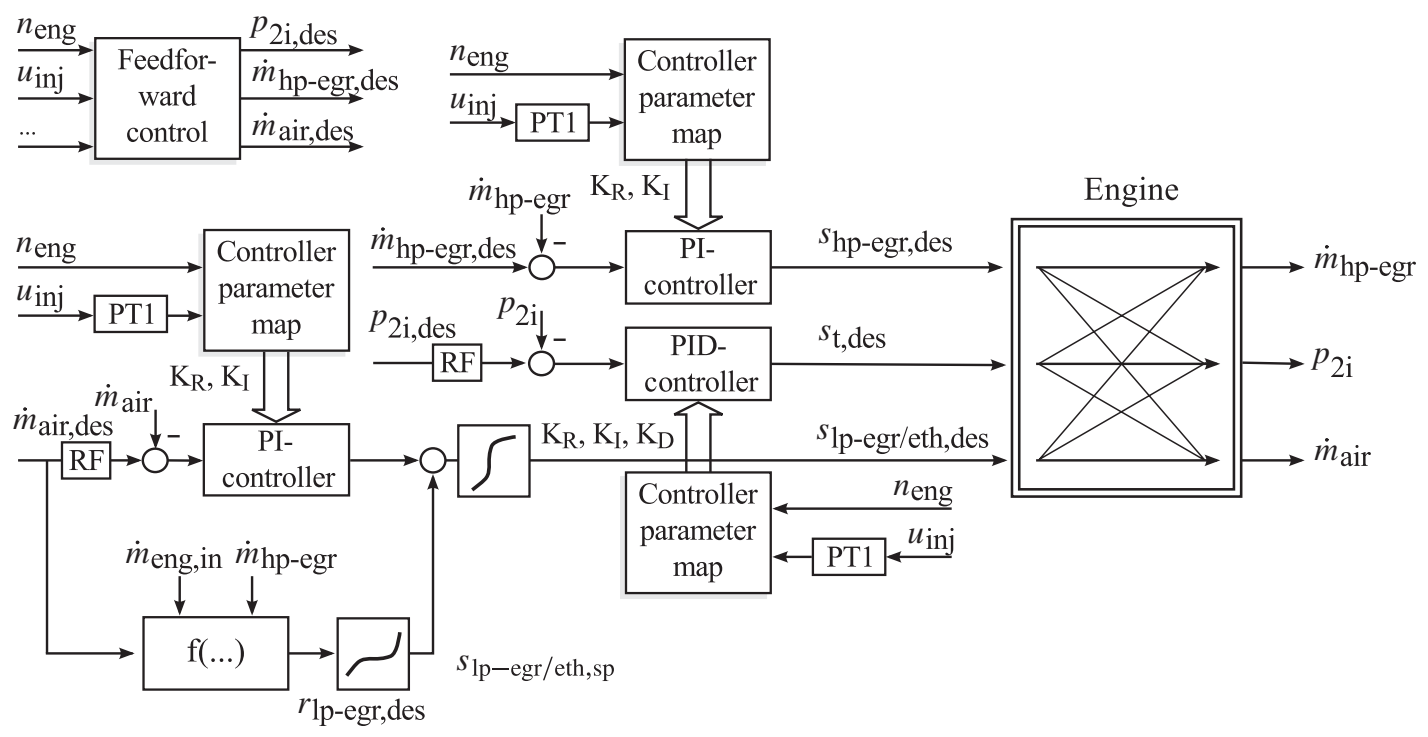

Figure 10

Block diagram of the control scheme with engine process.

The semi-physical model is locally linearised at all engine operation points and yields the transfer functions $G_{i j}(s)$, including the particular sign of the couplings. Additionally the transfer functions of the position controlled actuators are included in the plant models. Since the sampling time is a magnitude smaller than the fastest time constant of the controlled variables, the PI(D) controllers can be parametrised in the $s$-domain and then be transformed to discrete PI(D) controllers [33]. The linear multi-variable system in p-canonical structure is displayed in Figure 11.

In [4] the grey highlighted multi-variable system with the controllers $G_{\mathrm{C} 11}(s)$ and $G_{\mathrm{C} 22}(s)$ is regarded. In contrast to [4] here the HP-EGR mass flow rate is controlled with $s_{\text {hp-egr }}$ instead of $\dot{m}_{\text {air }}$. The coupling terms $G_{31}(s)$ and $G_{32}(s)$ are small and are neglected. Consequently the air mass flow controller $G_{\mathrm{C} 33}(s)$ only controls $G_{33}(s)$. The influences of $G_{\mathrm{C} 11}(s)$ and $G_{\mathrm{C} 22}(s)$ can be regarded as disturbances and are later compensated by a semi-physical control as presented later.

The linearised response characteristic between the desired position of the HP-EGR-valve $s_{\mathrm{hp}-\text { egr,des }}$ and $\dot{m}_{\mathrm{hp}-\text { egr }}$ in the closed control loop follows from Figure 11 as

$$
\frac{\Delta \dot{m}_{\mathrm{hp}-\mathrm{egr}}}{\Delta s_{\mathrm{hp}-\text { egr,des }}}=G_{11}(s)\left(1-\kappa(s) \frac{G_{C 22}(s) G_{22}(s)}{1+G_{C 22}(s) G_{22}(s)}\right)
$$

with the coupling factor

$$
\kappa(s)=\frac{G_{12}(s) G_{21}(s)}{G_{11}(s) G_{22}(s)}
$$

giving the coupling between the two control loops [34]. Similarly the response characteristic between $s_{\mathrm{t}}$ and $p_{2 \mathrm{i}}$ can

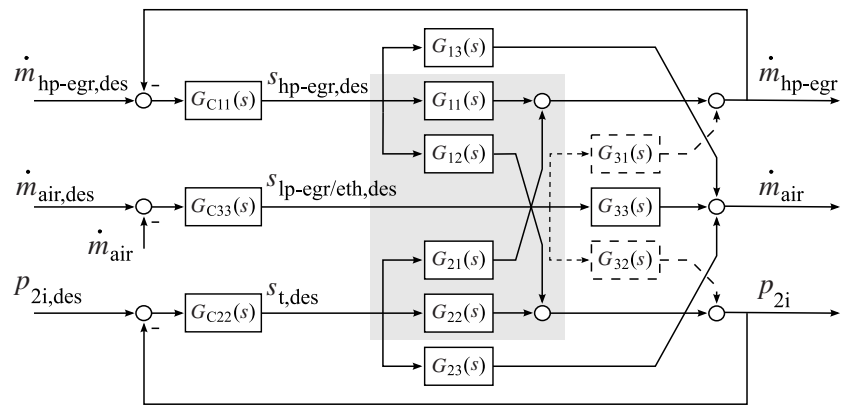

Figure 11

Decentralised controller structure and closed loop controlled system in p-canonical structure. By seqential tuning of the controllers $G_{C 11}(s)$ and $G_{C 22}(s)$ the interactions $G_{C 12}(s)$ and $G_{C 21}(s)$ are taken into account.

be described. The sequential SISO controller design with the compensation method is described in [8]. The transfer function of the controller follows from a desired transfer function of the closed control loop. With this method the time constant $T_{\text {des }}$ of the desired transfer function

$$
G_{\text {des }}(s)=\frac{1}{T_{\text {des }} s+1}
$$

gives the tuning parameter for the automated controller calibration. The resulting controller results according to [33] from the pole-zero cancellation controller

$$
G_{C}(s)=\frac{G_{\mathrm{des}}(s)}{G_{P}(s)\left(1-G_{\mathrm{des}}(s)\right)}
$$


in which $G_{\mathrm{P}}(s)$ is the response characteristic of the plant (3). A model reduction of the high order controller $G_{\mathrm{C}}(s)$ yields the parameters for the PI(D)-controller, see [35]. In the sequential controller design the $p_{2 \mathrm{i}}$-control loop is closed first, only accounting for the static coupling behaviour in Equation (4). Secondly the $\dot{m}_{\mathrm{hp}-\text { egr-control loop is closed }}$ accounting for the $p_{2 \mathrm{i}}$-control loop in Equations (3) and (4). The $\dot{m}_{\text {air-control loop is closed without regarding the other }}$ two control loops. The time constants $T_{\mathrm{des}}$ for the controller design are chosen as $0.7 \mathrm{~s}$ for the charge air pressure control and $0.25 \mathrm{~s}$ for the control of the two EGR loops.

In the following a novel semi-physical control based on model inversion for the $\dot{m}_{\text {air }}$-control loop is presented. It enables a decoupling of the $p_{2 \mathrm{i}}$-control loop and the

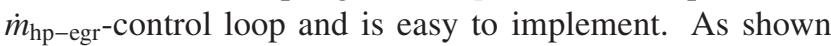
in Section 3 the LP-EGR rate $r_{\text {lp-egr }}$ depends mainly on the value of $s_{\text {lp-egr/eth }}$ at all engine operation points and can be expressed by a characteristic map as

$$
r_{\mathrm{lp}-\mathrm{egr}}=f\left(s_{\mathrm{lp}-\mathrm{egr} / \mathrm{eth}}\right)
$$

Then the mass flow rate in the LP-EGR path can be described by

$$
\dot{m}_{\mathrm{lp}-\mathrm{egr}}=\dot{m}_{\mathrm{eng}, \mathrm{in}}-\dot{m}_{\mathrm{hp}-\mathrm{egr}}-\dot{m}_{\mathrm{air}}
$$

A control deviation in the $\dot{m}_{\text {air }}$-control loop can be compensated according to Equation (8) by a change in

$$
-\Delta \dot{m}_{\mathrm{lp}-\mathrm{egr}, \mathrm{des}}=\dot{m}_{\mathrm{air}, \mathrm{des}}-\dot{m}_{\mathrm{air}}
$$

With Equation (2), Equations (8) and (9) follows the desired value of the LP-EGR rate as

$$
\begin{aligned}
r_{\mathrm{lp}-\mathrm{egr}, \mathrm{des}} & =\frac{\dot{m}_{\mathrm{lp}-\mathrm{egr}}+\Delta \dot{m}_{\mathrm{lp}-\mathrm{egr}, \mathrm{des}}}{\dot{m}_{\mathrm{air}, \mathrm{des}}+\dot{m}_{\mathrm{lp}-\mathrm{egr}}+\Delta \dot{m}_{\mathrm{lp}-\mathrm{egr}, \mathrm{des}}} \\
& =\frac{\dot{m}_{\mathrm{eng}, \mathrm{in}}-\dot{m}_{\mathrm{hp}-\mathrm{egr}}-\dot{m}_{\mathrm{air}, \mathrm{des}}}{\dot{m}_{\mathrm{eng}, \mathrm{in}}-\dot{m}_{\mathrm{hp}-\mathrm{egr}}}
\end{aligned}
$$

An inversion of Equation (7) allows to transform the desired LP-EGR-rate to the valve position

$$
s_{\mathrm{lp}-\mathrm{egr} / \mathrm{eth}, \mathrm{sp}}=f^{-1}\left(r_{\mathrm{lp}-\mathrm{egr}, \mathrm{des}}\right)
$$

This stationary model inversion for the $\dot{m}_{\text {air-control loop }}$ results in a semi-physical control which implicitly includes the air path dynamics in Equation (10). This control includes all couplings of $s_{\mathrm{hp}-\text { egr }}$ and $s_{\mathrm{t}}$ modelled with $\dot{m}_{\mathrm{hp}-\text { egr }}$ and $\dot{m}_{\text {eng,in. }}$. Being independent from measurements of $\dot{m}_{\text {air }}$ the feed forward control can anticipate the disturbances before their delayed propagation through the intake system.

\section{TESTBED RESULTS}

In Figures 12 and 13 the performance of the controllers at the testbed are shown at an engine operation point of $n_{\text {eng }}=2250 \mathrm{~min}^{-1}$ and $u_{\text {inj }}=15 \mathrm{~mm}^{3} /$ cyc. Setpoint steps

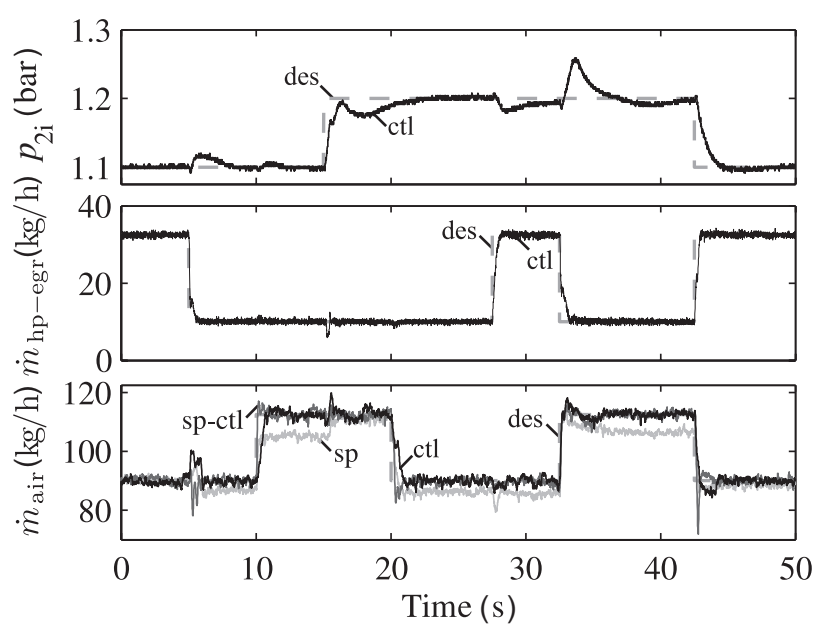

Figure 12

Measured steps of the desired values of the 3 controlled variables. Controller performance with semi-physical control (spctl), without semi-physical control (ctl) and with pure semiphysical control (sp) for the air mass flow controller.

are applied to all controlled variables. All controllers show good responses to changes in the setpoints of the three closed loops.

Regarding $p_{2 \mathrm{i}}$ the couplings of the other controlled variables are noticeable. Therefore a decoupling feed forward control or decoupling controllers are desirable. Secondly the closed loop control response of $\dot{m}_{\text {hp-egr }}$ shows a fast step response and almost no influence through the system couplings. In the $\dot{m}_{\text {air }}$-control loop the results for a controller with no additional semi-physical control (ctl), a controller with additional semi-physical control (sp-ctl) and the results of the pure semi-physical controller (sp) are presented. The combined controller with model inversion control shows a faster response to load steps than the pure PI-controller. At $42.5 \mathrm{~s}$ an undershoot below the setpoint is visible. Thus, a better adjustment of the two degree of freedom $\dot{m}_{\text {air }}$ control with better tuning of the reference shaping filter is desirable. It is further shown that the semi-physical control with model inversion is almost solely capable to control $\dot{m}_{\text {air }}$. Even if load steps are applied the deviation between the setpoint and measured $\dot{m}_{\text {air }}$ is not bigger than $8 \mathrm{~kg} / \mathrm{s}$. In summary the closed loop control met the specified time constants from the theoretical controller design.

\section{CONCLUSION}

In this contribution the static and dynamic properties of a two path EGR-system are presented. A semi-physical mean value model of reduced complexity models the two EGR-paths. The classical HP-EGR-system with VGTturbocharger shows couplings in the air mass flow rate $\dot{m}_{\text {air }}$ 


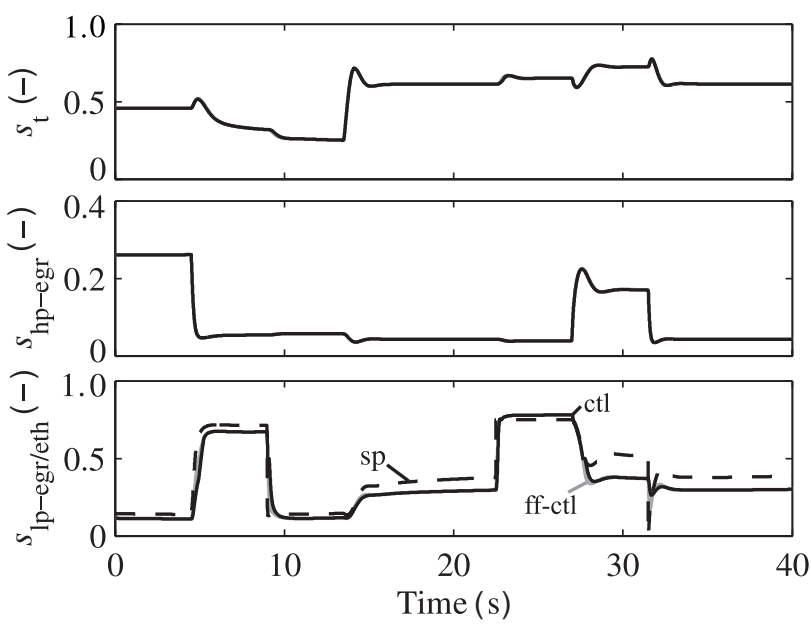

Figure 13

Manipulated variables related to Figure 12

and the charge air pressure $p_{2 \mathrm{i}}$. The additional LP-EGRloop introduces further couplings. Both the HP-EGR-valve and the VGT-actuator influence the mass flow rate through the LP-EGR-path. The actuators of the LP-EGR-path are weakly coupled with the process variables $\dot{m}_{\mathrm{hp}-\text { egr }}$ and $p_{2 \mathrm{i}}$. The LP-EGR-rate depends on the position of the LP-EGRvalve and the exhaust throttle plate and only marginally on the engine operation point or the position of the other airpath actuators. A model based approach with decentralised PI(D)-controllers and a physical based control is developed. Experiments showed a good control performance which met the specifications from the theoretical controller design.

\section{REFERENCES}

1 Hadler J., Rudolph F., Dorenkamp R., Stehr H., Hilzendeger J., Kranzusch S. (2008) Volkswagen's new 2.0 1 TDI engine for the most stringent emission standards - part 1, MTZ worldwide eMagazine 69, 12-18.

2 Weber O., Jörgl V., Shutty J., Keller P. (2005) Future breathing system requirements for clean Diesel engines, in 14. Aachener Kolloquium Fahrzeug- und Motorentechnik, Aachen, 2005.

3 Jörgl V., Shutty J., Roth D., Weber O. (2007) Taming the complexity of future air breathing systems by smart engineering, in 7. Internationales Stuttgarter Symposium - Automobil- und Motorentechnik, Stuttgart, 2007.

4 von Pfeil K., Zimmerschied R., Isermann R. (2007) Nichtlineare Identifikation des Luftpfads von aufgeladenen Dieselmotoren und automatisierter AGR-/VTG-Reglerentwurf, Automatisierungstechnik 55, 352-359.

5 Ammann M. (2003) Modellbasierte Regelung des Ladedrucks und der Abgasrückführung beim aufgeladenen PKW-Common-Rail-Dieselmotor, PhD Thesis, Eidgenössische Technische Hochschule Zürich.
6 Jung M. (2003) Mean-Value Modelling and Robust Control of the Airpath of a Turbocharged Diesel Engine, PhD Thesis, University of Cambridge, Cambridge.

7 van Nieuwstadt P.E., Kolmanovsky M.J., Moraal I.V. (2000) EGR-VGT control schemes: Experimental comparison of a high-speed Diesel engine, IEEE Contr. Syst. Mag. 63-79.

8 von Pfeil K. (2009) Model-based control of charging pressure and EGR of turbo-charged Diesel engines, in Tagung Elektrisches Management Motorischer Fahrzeugantriebe, Haus der Technik.

9 Eriksson L. (2007) Modeling and control of turbocharged SI and DI engines, Oil Gas Sci. Technol. 60, 4, 523-538.

10 Guzzella L., Onder C. (2010) Introduction to Modeling and Control of Internal Combustion Engine Systems, Springer, Berlin, 2nd edition.

11 Heywood J.B. (1988) Internal Combustion Engine Fundamentals, McGraw-Hill Publishing Company.

12 Zahn S., Isermann R. (2007) Development of a crank angle based engine model for real-time simulation, in 2nd Conference: Engine Process Simulation and Supercharging, Berlin, June 2007.

13 Zahn S., Isermann R. (2008) Crank angle synchronous modelling and real-time simulation of Diesel engines for ECU function development and testing, in 9th Int. Symp. On Advanced Vehicle Control, Kobe, 2008.

14 Mrosek M., Zahn S., Isermann R. (2010) Parameter estimation for physical based air path models of turbocharged Diesel engines - An experience based guidance, SAE Int. J. Engines 2, 2, 570-583.

15 Mrosek M., Isermann R. (2010) On the parametrisation of turbocharger power and heat transfer models, in IFAC Symposium Advances in Automotive Control, Munich, 2010.

16 Isermann R., Münchhof M. (2011) Identification of Dynamic Systems, Springer.

17 Kolmanovsky I., Moraal P., van Nieuwstadt M., Stefanopoulou A.G. (1997) Issues in modelling and control of intake flow in variable geometry turbocharged engines, in Proceedings of 18th IFIP Conference on System modeling and Optimization, Detroit. July 1997.

18 Wahlström J. (2009) Control of EGR and VGT for Emission Control and Pumping Work Minimization in Diesel Engines. PhD Thesis, Linköping University, No. 1256.

19 Zimmerschied R. (2008) Identifikation nichtlinearer Prozesse mit dynamischen lokal-affinen Modellen: Maßnahmen zur Reduktion von Bias und Varianz, volume 1150 of Reihe 8, Meß-, Steuerungs- und Regelungstechnik, VDI-Verlag, Düsseldorf.

20 Mollenhauer K., Tschöke H. (2010) (eds) Handbook of Diesel Engines, Springer, 1st edition.

21 Mrosek M., Isermann R. (2010) Dynamic reference value generation for the control of a Diesel engine with HP- and LP-EGR, in Proceedings of the ASME 2010 Dynamic Systems and Control Conference, Cambridge, Massachusetts, USA, September 2010, ASME.

22 Guzzella L., Amstutz A. (1998) Control of Diesel engines. IEEE Control Systems 18, 5, 53-71. 
23 Schloßer A. (2000) Modellbildung und Simulation zur Ladedruck- und Abgasrückführregelung an einem Dieselmotor, Number 860 in Fortschritt-Berichte VDI, Reihe 8. VDIVerlag, Düsseldorf.

24 Ortner P., del Re L. (2007) Predictive control of a Diesel engine air path. IEEE Trans. Control Syst. Technol. 15, 3, 449-456.

25 Richert F. (2006) Objektorientierte Modellbildung und Nichtlineare Prädiktive Regelung von Dieselmotoren, Number 1092 in Fortschritt-Berichte VDI, Reihe 8. VDI-Verlag, Düsseldorf.

26 Rückert J. (2005) Modellgestützte Regelung von Ladedruck und Abgasrückführrate beim Dieselmotor, number 1064 in Fortschritt-Berichte VDI, Reihe 8. VDI-Verlag, Düsseldorf.

27 Schwarzmann D. (2008) Nonlinear Internal Model Control with Automotive Applications, Logos Verlag Berlin, 2008.

28 Rajamani R. (2005) Control of a variable-geometry turbocharged and wastegated Diesel engine. Proc. Inst. Mech. Eng. Part D: J. Automobile Eng. 219, 11, 1361-1368.

29 Jankovic M., Jankovic M., Kolmanovsky I. (2000) Constructive Lyapunov control design for turbocharged diesel engines, IEEE Trans. Control Syst. Technol. 8, 2, 288-299.
30 Müller V., Christmann R., Münz S., Gheorghiu V. (2005) System structure and controller concept for an advanced turbocharger/EGR system for a turbocharged passenger car diesel engine, in SAE Powertrain E Fluid Systems Conference $\mathcal{E}$ Exhibition, number SAE 2005-01-3888, San Antonio, TX, USA, October 2005.

31 Heuck M., Feldt M., Eichhorn M., Horn A. (2008) Modellgestütztes AGR-Management für zukünftige Luftsysteme aufgeladener Dieselmotoren, in Steuerung und Regelung von Fahrzeugen und Motoren - AUTOREG, Baden-Baden, 2008.

32 Chauvin J., Grondin O., Moulin P. (2009) Control oriented model of a variable geometry turbocharger in an engine with two EGR loops, in 2009 IFAC Workshop on Engine and Powertrain Control, Simulation and Modeling, Rueil-Malmaison, France, 2009

33 Isermann R. (1989) Digital Control Systems: Fundamentals, Deterministic Control, Springer, Berlin, 2nd rev edition.

34 Isermann R. (1991) Digital Control Systems: Stochastic Control, Multivariable Control, Adaptive Control, Applications. Springer, Berlin, 2nd rev edition.

35 Lee J., Edgar T.F. (2004) ISE tuning rule revisited, Automatica 40, 1455-1458. 